\title{
Digital Marketing Plan for CubiCasa OY USA
}

\author{
${ }^{1}$ Adomas ZAIKAUSKAS, ${ }^{2}$ Ricardo Fontes CORREIA and ${ }^{3}$ Carlos R. CUNHA
}

\author{
${ }^{1}$ Bachelor of International Business and Communication - ISM University of Management and \\ Economics, Vilnius, Lithuania \\ ${ }^{2}$ Instituto Politécnico de Bragança, Campus de Santa Apolónia, 5300-253 Bragança \\ Portugal; CiTUR Guarda - Centro de Investigação, Desenvolvimento e Inovação em Turismo \\ ${ }^{3}$ UNIAG; Instituto Politécnico de Bragança, Campus de Santa Apolónia, \\ Bragança,Portugal
}

Correspondence should be addressed to: Ricardo Fontes CORREIA; ricardocorreia@ipb.pt

Received date:25 March 2021; Accepted date:25 August 2021; Published date: 19 January 2022

Copyright (C) 2022. Adomas ZAIKAUSKAS, Ricardo Fontes CORREIA and Carlos R. CUNHA. Distributed under Creative Commons Attribution 4.0 International CC-BY 4.0

\begin{abstract}
The aim of this paper is to provide an analysis that will be necessary for the development of a future digital marketing plan for CubiCasa OY with the main goal to attract new customers in the United States market. Specifically, the following topics are addressed during the analysis: external and internal examination of CubiCasa in the United States market to assess the current company's position in the market; performing empirical research to figure out the most important aspects for real estate photographers and businesses.

It was followed a qualitative research method with semi-structured surveys sent by Google forms to eight customers who use floor plan creation tools and operate in the US.

The findings will help to analyze and make an appropriate decision when adapting it to a digital marketing plan and help to improve customer reach and brand awareness among the United States floor plan makers and companies specializing in real estate business.
\end{abstract}

Keywords: Digital Marketing, Case Study, Qualitative Research, Digital Channels

\section{Introduction}

CubiCasa is a Finnish Startup, specializing in mobile application solutions for real estate photographers. It serves the real estate photographers' marketplace by taking the provided video footage and giving back a generated floor plan within the application. The headquarters of the company are based in four different locations including Oulu and Helsinki in Finland, California in the United States, and Vietnam as their technical hub. Operations take place all around the globe, however adaptation of marketing decisions to each market is a crucial part for the success of the company. Different markets are prone to have different needs and perceptions of

Cite this Article as: Adomas ZAIKAUSKAS, Ricardo Fontes CORREIA and Carlos R. CUNHA (2022)," Digital Marketing Plan for CubiCasa OY USA", IBIMA Business Review, Vol. 2022 (2022), Article ID 476918, DOI: 10.5171/2022.476918 
the products and services provided by the companies, therefore this has to be differentiated for every market individually. This is because certain markets view conventional and primarily digital marketing mix, which emphasize the correct service characteristics, as essential criteria for purchases. The focus of this final thesis is on real estate photographers for both, individual and larger companies in the United States of America, with an emphasis on how to target them with the appropriate marketing strategy.

The CubiCasa company was established in 2014, December and, with technological advancement and marketing decisions, has been growing its customer base ever since. In the market of the United States, it is renounced as one of the biggest players in the field for the creation of floor plan applications. Competition in this niche market is high since the barriers to enter the market are virtually non-existent and new competition could rise up any day with a new technology which could be superior to the existing one and attract a bigger audience to the platform. Attracting new and keeping existing customers is extremely importantly seen, as the customer basis is one of the crucial aspects for the success of this particular service.

CubiCasa's application is most widely used in the United States and Finland, among several other European countries which are a small margin of the whole operation in total.

The United States is the biggest market for floor plan creation and it has the highest customer number for the company at this moment. Increasing the number of real estate photographers and companies working in this sphere would potentially have a positive impact on the whole real estate market, since floor plans are one of the key features which help market the property. The company would also benefit from this seen as this could lead to the increase of customers, improved market size and market share of the company. Hence, increasing the number of real estate photographers and companies operating in the United States should be an ambition of the CubiCasa.
Before any strategical decision could take place, examination of internal and external factors is crucial for success in the market. It is vital to understand what impacts you from both, inside and outside of an organization. Evaluating the details of a particular situation allows companies to see whether certain strategy or decision will work. Most real estate photographers use conventional tools such as DSLR cameras to capture the spaces and special equipment cameras to capture the floor plans which would later be transferred to digital tools to complete the process. CubiCasa is a fully digital company with only digital presence in the market; it can target the real estate photographers with the promotion of digital approaches which would not require as much effort from the photographers as the currently used methods. Country targeting with a detailed focus on certain demographics and interests and behaviors of the people could be beneficial for the organization, since adaptation could target the ones who are the most interested in the services that the CubiCasa provides. During the process, more real estate photographers and floor plan makers in the United States could be attracted to choose CubiCasa as a service provider. Thus, the digital marketing plan is one way to attract new customers with the possibilities digital channels possibility to target a specific group of people.

This paper presents the deep analysis process for understanding the most important perspectives of CubiCasa OY for future establishment of a full Digital Marketing Plan. Beside a literature review, the empirical process is detailed, analysis results and some preliminary proposals are also presented.

\section{Literature Review}

The relationship between customer and marketer is beneficial for both sides, seen as the main objective of marketing is superior value creation for a specific customer. Due to this, the customer provides value to the marketer in return, which helps the marketer with maintenance and provision of satisfaction for existing customers (Armstrong and Kotler, 2010). Business environment is highly influenced by digitalization, which 
can also be applied for marketing. According to Kotler (2009), the Internet is seen as not just another means of advertising or another sales channel but more like a tool which can change the way a company operates fundamentally. This includes the way orders are taken from the customers, how the value is given back to them, and the way business is done (Kotler, 2009).

Digital marketing can be defined as a form of marketing that uses the media for advertising by collecting available data and by using technology in order to be able to achieve the standard objectives of marketing (Chaffey \& Chabwick, 2019). For digital marketing to be of use, the company has to set out certain goals which it wants to reach by utilizing the power of digital technologies (Chaffey, 2018; Todor, 2016; Wymbs, 2011). This involves the formation of online channels made specifically for marketing by applying technology, which in turn should allow achieving targets of retention of customers and profitable acquisition (Chaffey, 2016). Furthermore, digital marketing deals with the company's presence in the digital environment by using tools such as social media, website, and smartphone applications, all of which are great channels for fast information sharing and communication (Chaffey and Chabwick, 2019). Over recent years, new and innovative approaches to marketing have been demonstrated by marketing people in which they started to exploit social media networks, websites and applications in a way that allows the intended content to reach the consumer via targeted and direct channels (Armstrong, Adam, Denize, \& Kotler, 2014).

The first aspect of digital marketing is the content the company is trying to show to the general public. Content marketing is a company procedure in marketing that allows providing valuable and relevant information in both written and visual forms. The purpose of this is to draw new customers, interest them in a conversation with a desire to turn them to profitable customers. (Content Marketing Institute, 2015) Putting this content out on to the Internet and using different mediums. Social media are a massive market. Social media converted marketing understanding. They created new means of communication with customers, who could have never been approached before and established ways to increase brands' awareness with higher reachability of customers all around the globe (Comscore Media, 2009). Furthermore, the market size of social media users is constantly growing in the whole world and there are new social medial platforms appearing every now and then (Hoffman \& Novak, 2012).

Most consumers and companies understand social media marketing as different channels like Facebook, Instagram, LinkedIn, etc., that have most users in each country, in which advertising has to be made. Hence, this is important their aspects as capturing customers' generated content and encouraging it such as company evaluation and product reviews on either of these platforms. (Chaffey \& Chadwick, 2018). Facebook, as one of the many social media platforms, provides advertising to customers and platform users can interact with the ads with impressions "share" "like" "comment" and can also view how their friends on the platform chose to interact with advertisements (Dehgani \& Tumer, 2015). Another option could be to put your brand on Instagram. New companies or yet to be publicly known ones can use Instagram to endorse their customers, to gain engaged followers, to create awareness for the company, or to simply engage with the customers (Virtanen, Bjork, \& Sjostrom, 2017). Instagram gives an opportunity for businesses to interact with their customers by engaging with them in their posts or by having an open discussion in the comment section. This provides endorsements, which can then be seen by other users of the platform (Miles, 2014). The recent approach to marketing is through influencers. Some of these users build an immense follower audience and can be used for marketing. It is an important part for some businesses since it communicates directly with a prospective customer and focuses on these individuals who are decision makers. Influencers are an important part of the sales process (Brown, Hayes, 2008). 
When it comes to searching for anything specific, searching online is an activity done by most Internet users, and search engines are the most widely used option for this (Sen, 2005). In Internet marketing and commerce, search engines are becoming more and more important (Green, 2003). Search engine marketing is a digital marketing approach to search engine like Google. By making specific adjustments to the website and using techniques to comply with the search engine algorithm, webpages may appear in a first few spots of the results' page (Paraskevas, Katsogridakis, Law, \& Buhalis, 2011). One way to appear at the top of the search list is by modifying the site code, which can further improve sellers' listing in the search engines' results pages, making them more relevant and optimized for search engine algorithm (Rashtchy, 2004). SEO or search engine optimization is a technique used to optimize every single page of your website results to stand out better in the result list and this way bringing more visitors to your page. SEO encompasses specific queries to the website that are relevant to the represented business and, when those targeted queries are used, appearing at the first pages. PSM or paid search marketing is a form of paid results page where the advertiser, for example Google, places you at the top of results' page when a specific keyword is entered. Keywords come with a price and are determined by the CPC or cost per click, which are calculated on the keywords traffic (Li, Lin, Lin, \& Xing, 2014).

PSM is also called sponsored links or sponsored list, which is operated by search engines in the form of sponsored or paid results, where an advertisement is displayed in a pre-specified region of a search result page along with web search results. Search engines charge placement fees tied to the price of the relevant keywords, which are primarily determined by keywords auction and measured by cost per click (CPC), and the number of clickthrough the advertisement receives.

Start-up companies undergo serious challenges and have to use their resources effectively. Innovations are often undertaken by new ventures and startups, which allow them to change their development still in the early stages (MacDougall \& Oviatt, 1996). However, in cases of early development, issues such as need for alignment of internally acquired resources to the external conditions and resource scarcity have to be tackled early on (Hanlon \& Saunders, 2007; Katila \& Shane, 2005). Due to the ever changing and unstable digital environment, problems as the ones mentioned above are especially valid for new businesses working under these types of conditions (Courtney, Kirkland, \& Viguerie, 1997; Sirmon, Hitt, \& Ireland, 2007). Additionally, Clarke (2013) argues that financial maturity is more important than how many years have passed if a company wants to progress from being a startup. According to the author, any company that is still trying to reach profitability can be classified as a startup.

A case example of the usage of digital marketing is the company CubiCasa, the main objective of which is attraction of new and retention existing customers. Based on the arguments above, CubiCasa is still considered a startup. It is of high importance for the success of the company to implement marketing strategies that would help it grow but would still be cost effective. According to Todor (2016), digital marketing is less costly when compared to conventional marketing and can attract bigger audience without additional fees. Furthermore, the Internet could help improve operation efficiency for small, medium enterprises (SME) because the targeted specific market reach could be widened (Todor, 2016).

Considering the theoretical approach and the aim of this thesis, digital marketing plan fits the company's purpose and it should be applied in order to establish a wider customer base without exceeding the planned budget.

\section{Empirical Research}

An empirical research study is done to get a deeper and wider understanding of the behavior and the needs and wants patterns of companies and individual real estate photographers using floor plan making software in the USA market. This research 
provides breakdown of the obtained information and the data that will be used to prepare an appropriate digital marketing plan for CubiCasa to attract more real estate photographers and floor plan makers living in the USA.

\section{Aim and Objective of the Research}

The aim of this research is to analyze and determine the aspects, which have an effect on consumers when it comes to choosing the software for floor plan making for their operations and to deciding which marketing tools to apply and which are the most effective for bringing more customers living in the US to CubiCasa. To achieve this, the objectives are defined as follows:

- Choose the appropriate theoretical framework;

- Conduct surveys with existing CubiCasa clients and companies, in order to determine which factors have the most influence when choosing floor making software and the correct digital marketing tools to reach out to viable customer for CubiCasa in the US market;

- Analyze the data collected from questionnaires and assessing them to make a relevant solution for the development of digital marketing plan in managerial solution.

\section{Theoretical foundation of the research}

To create a digital marketing plan for CubiCasa that is appropriate for the US market, it is necessary to know what is crucial for and preferred by the floor plan makers. To extract the information that is necessary and relevant, theoretical frameworks have to be used. This research applies three different frameworks.

The first model used for the questionnaire as a background for questions is called $6 \mathrm{M}$ marketing communication model presented by Dolan (1997). The model consists of six aspects of marketing communication - market, mission, message, media, money, measurement. Addressing each component of $6 \mathrm{M}$ model is crucial. D'amico (2015) defined them as:

- Market - group of people company is targeting and the tools used to target them are correct;

- Mission - the objective of the communication, the message should be in correlation with the end goal.;

- Message - points that have to be communicated to customer, provides specific points with the most necessary information;

- Media - communication channels to get the message to the target audience;

- Money - budget to prepare, start and maintain the marketing campaign;

- Measurement - assessed data on how well the marketing campaign was done.

The second theoretical framework used is the RACE model introduced and revised by Chaffey (2020). This model works specifically for digital marketing and is compiled of four main steps and one preparation stage as defined in Figure 1. 


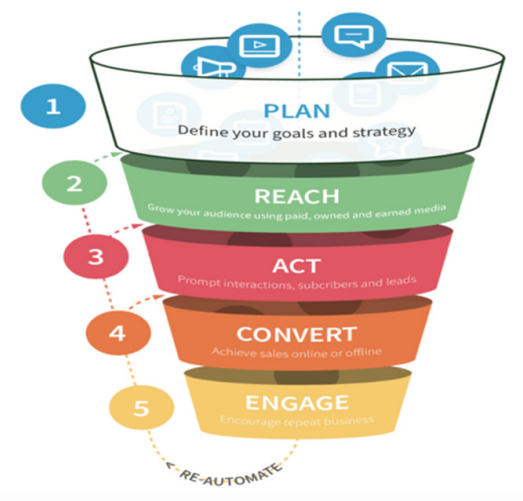

Figure 1: The RACE planning system

Race framework consists of 5 stages and these are as follows:

1. Plan - Establish SMART KPIs, define target for digital channels, focus investment in content marketing, digital media and experiences. Define segmentation, targeting and positioning of the marketing campaign and value proposition;

2. Reach - Draw people to your hub with content. Promote the content with other blogs by allowing sharing of other blogs, networks and influencers. Key measurements include unique visitor, value per visit, and followers;

3. Act - worth finding with relevant content that is inspirational and is creating leads. Key measurements are lead conversion rate, time on site, interactions;

4. Convert - invest in marketing, CRO, marketing automation and remarketing to contextual that drives conversions. Key measures' sales, revenue, average basket value;

5. Engage - Loyal customers that spread the message via social testimonies, repeat purchases and refer to others. Key measures are repeated purchases, advocacy, and loyalty.

\section{Research Method and Data Collection Method}

For this research, qualitative research method is used. According to Monique, Inge, and Ajay (2010), qualitative research allows analyzing people's experiences, actions, opinions, beliefs in detail by conducting a structured, specific set of methods in interviews, focus groups, and observations. This research method also lets the researcher see outside their formed opinion about the topic and see outside his/her beliefs on the subject (Monique et al., 2010). The most distinctive feature of qualitative research is that the approach allows you to identify issues from the perspective of your study participants and understand the meaning and interpretations that they give to behavior, events, or objects.

Primary data collection method was used in this research since the market for floor plan making applications is very niche segment, is in early stage and not many sufficient and reliable secondary data collected exist to this day. With this in mind, primary data will be more tailored and valuable in this case. Specifics like demographics of the companies questioned can be defined and specified to researchers' needs. This brings complete control of the data collection by being more consistent by having the same questions and reliability and relevance to this topic.

Primary data collection is conducted by making structured survey via Google Forms. Surveys are chosen because of the different time zone with the US market and big real estate companies preferring this type of method for convenience. Crosssectional study surveys can provide both the insights the researcher is expecting to have and the other opinions not thought about by the research, which allows for multiple outcomes to be reached at once. Descriptive research is conducted and it 
will provide information about how variable of interest occurs in a specific demographic. A total of 21 questions were asked.

\section{Data Analysis Methods}

The purpose of this research is to figure out the main factors that are the key drivers in customer selection of companies who provide floor plan making application from the marketing perspective. To obtain meaningful results from the data collected by conducting semi-structured surveys, deductive data analysis approach was used. Obtained data were analyzed using The Matrix Method (MM). The basis of this method was introduced by Gordon and Langmaid (1988). The findings of the research were analyzed to discover the patterns which, in return, would provide a managerial solution.

\section{Analysis Results and Preliminary Proposals}

CubiCasa is a startup company founded by two Finnish men. The company was officially established in December, 2014 in Oulu, Finland. The company has three subsidiaries and one technical center. The main headquarters are located in Oulu, Finland and other offices are established in Helsinki, Finland and Palo Alto in California, the United States. The IT operations are located in Ho Chi Minh, Vietnam. The company currently employs 142 people across the 4 locations. According to Haaramo (2018), CubiCasa was the first non-American company to be accepted into Modern Ventures' real estate accelerator program in Chicago. Revenue for 2019 was an estimate of 2 million euros. The company is the market leader in the very price-sensitive Finnish market and is also one of the major players in the US floorplan market. The company operates mainly in two key markets: real estate and informational technology (IT). It is best known for the "CubiCasa" application it has created, which is available on both Google PlayStore and Apple AppStore. The main function of it is to create 2D and 3D floor plans within a few minutes with the help of a smartphone. It does not require any special equipment and prior knowledge of floor plan creation. CubiCasa mainly focuses on real estate photographers and small business owners who make floor plans with dedicated software or expensive special equipment. The company focuses on Business-to-Business principle, seen as both, customers of CubiCasa and users of the app, have to be registered companies in order to make a floor plan. The company's vision is related to interior space knowledge, building of the most scalable interior, data understanding technology and its related products.

\section{USA Market}

CubiCasa is a digital business that operates worldwide due to the fact that it is a business performed fully online. According to internal company data, it is estimated that around 95\% percent of all users, real estate photographers and real estate companies, are located in the market of the United States. This shows that this market is the biggest from the ones that "CubiCasa" serves. The United States of America is the largest real estate market for residential property and the commercial spaces in the world, with a market size of 3,418.1 (USD Billion) with the closest competitor Japan with 881.4 (USD Billion).

The company is seeking to increase both the customer number and the number of purchases made by current clients operating in the United States, by providing learning material for floor plan making and the information on how to grow your photography business by incorporating floor plan making into daily operations. This would benefit the company by increasing the number of customers and orders being made in the United States, as it would also ensure better position in the market itself.

To attract new customers in the specific market segment, it is important to create and implement a digital marketing plan based on distinctive criteria. By utilizing the right marketing techniques that are effective in the real estate market as well as with the current trends that are prone to show positive impact, the company can expand their customer base. 


\section{Marketing Mix}

Services marketing mix is formed from the 7Ps of marketing: Product, Promotion, People, Process, Price, Place and Physical evidence. The business operates in digital environment so the actual place of it cannot be identified apart from digital environment in terms of being online.

Product: The product of CubiCasa is an application which can be downloaded from both Apple AppStore and Google PlayStore. The website can be seen here https://www.cubi.casa/. Users have to sign-up on the website or through the application to be able to use the application. A legal company name and VAT identification number, which is optional, are required to create an account. Creating a new floor plan requires address, street number, apartment number, city, postal code, state, and country and you can add any additional information which could be relevant for the details about the real estate regarding the location. After creation of the floor plan, which takes up to one business day, you can customize it on the website based on your preferences, for example by changing the proportions, fonts, colors, etc.

Price: Two options exist for using a floor plan application. First option is "Pay-asyou-go President", which costs $\$ 34.90$ per scan and is mostly used by people who scan up to 2-3 houses per month. Second one is "CubiCasa Certified photographers", which costs $\$ 24.43$ per scan. When choosing the later, a discount of 30 percent is given to incentivize companies to become certified photographers and the only requirement for this is to make around 30 scans per months. At this point, this price is the best among all competitors in terms of services provided and the time spent doing accurate floor plans, this was done by implementing Cost leadership pricing and being the cheapest option on the market.

Promotion: CubiCasa puts all its effort to digital advertising. Daily activities of the marketing department include a wide variety of different tasks.

Place: CubiCasa has three offices, two in Finland and one in The United States and a technical headquarter in Ho Chi Minh City,
Vietnam, where all of the scans are made into finished floor plans. European offices are responsible for marketing activities. American division's responsibilities include business growth, search for investments and customer attainment and support. Vietnamese courters are responsible for the IT and the technical side of the processes, during which room scans are converted into the finished product and are also responsible for the improvement of the technology used for the scanning application.

People: CubiCasa employs around 140 people in their four offices; every employee is hired and interviewed by HR manager and usually one of the two co-founders joins to have a chat and evaluates every single candidate himself. Start-up environment is said to be less hierarchical and communication is less formal. Decisions and suggestions come from both bottom-up and top-down, which ensures that even the employees with least responsibilities can suggest ideas for the company's advantage. Customer service is carried out by the customer support team via email, live chat or calls. Customer relationship management is done with a software in which all of the organization can see all of the information and conversations that have happened in one place.

Process: The submission of the video footage is sent to the internal servers of the company, which are analyzed by the technical team with a standardized program which transforms raw footage to 2D and 3D floor plan. Technicians ensure that no flaws occur in the process and if something goes wrong, they correct the case manually. This takes place in the technical headquarters in Vietnam.

Physical evidence: Company timely and frequently publishes on their social media, their website, the blog of the CubiCasa success stories, and the actual results obtained by the customers with their real reviews and the ratings they have given the company for its service. 


\section{PESTEL Analysis}

PESTEL framework is used to assess the external environment of CubiCasa in the United States of America market.

Political: As with any industry and market concerning business, political decisions play a big role for the companies and startups. Political stability is one of the crucial aspects for every company since it can have a strong impact on the profitability and overall lifespan of the company in the desired country. CubiCasa has to consider a few things while operating in the United States. The intellectual property rights, with the agreement, seem to be in consideration, and the new companies emerging in the Chinese market should not be a problem with intellectual property theft. Trump tax deduction also plays a big role, seen as with it, the corporate tax has been reduced from 35 percent to 21 percent, which allows any company to invest the funds elsewhere for the benefits of a company, for example in $R \& D$ or any other profitable business operation. In turn, such investments allow the United States to stay a competitive country for corporations.

Economical: Economic factors generally directly affect market conditions. Even a little financial change can move the economy and change the circumstances for a business. Economy growth leads to industry growth. The United States has the biggest and most advanced IT service in the world. 32 percent of all information technology market, or approximately 1.7 trillion United States dollars, is situated in North America, mostly the United States. The whole market is approximately 5.2 trillion USD. The market is expected to grow by $3.7 \%$ in 2020 with an optimistic forecast of $5.4 \%$ as the highest and $1.9 \%$ as the lowest growth rate. The IT sector in the United States, which is part of the information sector, employs around 11.8 million people and, according to CompTIA (2019), there are approximately 525,000 companies working in this sphere and 40,500 tech startups established in 2018. In total, the working-age population (between15-64) was an approximately 206.2 million people in July of 2020, while the information sector employed 27.66 million people in 2019, which is still currently growing. The overall growth of the industry is a promising sign and due to expansions of the industry, with more professionals in the labor market, no shortage in this sector should be felt.

Social: During the recent shift of the consumer market, with an increasing use of social media, trends from computers to smartphones have shifted drastically. Due to better mobility provided by a mobile device, computers have become a professional tool, while smartphones - a daily accessory for the masses. However, nowadays, the shift in the usage of tablets and smartphones in professional life is becoming more prominent. This is because increasing numbers of professionals are looking for ways to work more conveniently and more affordably, which can be provided by increased mobility, ascribed to mobile devices. Based on current trends, the market might expect further expansion of mobile phone usage with applications and their continuous development doing most of the work which needs to be done. Due to this, more smartphones, which are the main tool for CubiCasa's customers, are expected.

Technological:

Technological advancement is a crucial point for the sales of applications. Every advancement can bring additional features and improvements for a software. With improvements, software engineers can improve the product without the drawbacks on the performance and overall user experience. The United States is the most advanced market for technological improvement for both, hardware and software. Hubs like Silicon Valley, where most entrepreneurs and IT engineers are located, are a great way to build networks. Internet of things (IoT), artificial intelligence (AI), Big data/analytics, virtual reality, are some of the hottest topics in the IT industry today and every part of life is shifting into the digital world and the cloud. The most viable solution for the company will be implementing the upcoming LiDAR (Light Detection and Ranging) to smartphone, which could mean an absolutely automated process and an 
increased accuracy of the scans, which every Apple iPhone user will have.

Environmental: With the ongoing Covid19 crisis, the whole world is increasingly relying on the digital working space. With the shifting focus on environmental issues, the crisis is causing lower than usual levels of pollution around the globe, which in turn is a positive impact for the environment. This trend might stick and it would benefit the IT sector the most, seen as the work done in this sector is mostly remote as it is.

Legal: The United States of America has the biggest IT sector in the world and is trying to ensure that the technology spillovers and stealing of the technology would not occur. Legislations are made to ensure that every tech company would be sure that their property rights in intellectual property would be protected against any illegal actions. There are four types of essential rights for software: patents, trademarks, trade secrets and copyrights. These ensure that a company, in this case a software development company, can get a patent, for example, for the feature that they have invented without anyone else using it. Copyright can protect the particular way the idea of the feature, in this case a software code, is expressed.

\section{Porter's Five Forces Model}

Five Forces model allows organizations to asses beyond the actions of their competitors and other factors that could affect the overall market. Michael Porter (1979) identifies five forces that sum up the whole environment and affect the organizations' overall success and profitability. These are:

Competitive Rivalry: Being an Internetbased service, CubiCasa encounters a lot of competition both directly and indirectly. Information travels fast and anyone can attain the needed resources as well as develop a technology relatively quickly. When the competition is steep and the new entrants can occur any day, if the market is still growing or is not overwhelmed by the current companies operating in this market or one player is not too big to overtake his position or existing clients with better technology or better marketing techniques. Switching costs between any application for mobile phones is relatively small or non-existent, which is another threat worth consideration, since clients can switch to another provider very easily, without any high-cost of doing so. Customer loyalty, defined by Oliver (1999), is "a deeply held commitment to re-buy or re-patronize a preferred product/service consistently in the future, thereby causing repetitive same-brand or same brand-set purchasing, despite situational influences and marketing efforts having the potential to cause switching behavior.". Repetition of the use for the same mobile application, in this case, can be obtained by providing higher than competitions' perceived value of the services CubiCasa provides. Zeithaml (1988) described perceived value as an overall assessment of the utility of a service or product on a basis of what is received by what is exchanged for it. Providing value to the customer could be the only option for mobile application, which provides no tangible assets in exchange for the price the customer is paying.

Buyer Power: High bargaining power of buyers can easily influence the overall position of the company in the market since the application can be purchased easily or downloaded for free in both AppStore and Google PlayStore. The biggest buyers in this market are the large real estate companies which also have departments for floor plan making and photographing. Since one company can influence a large number of orders, this can also dictate a price for which the service is carried out and, in these terms, less positively influence the company's revenues for the time, unless there is a technological superiority or if the company is the only market player. If the prices are dictated by the large companies with big purchases and the company does not comply with the requested prices, it is easy for them to switch to any other service providers without any big costs for the company. Waterbed Effect should not take place in this type of market since, the bigger players, even if they are purchasing for lower prices, should make life for the smaller companies worse than buying for a larger sum. Being a service rather than a product, the typical costs for a product do not exist and in this case, CubiCasa should 
try to win back on the revenues by increasing the prices to smaller companies and individuals with lower purchases for the service.

Supplier Power: IT industry, for the development of applications for mobile phones, has many suppliers and large portion of this is either in the house development with the team, hired or outsourced to other parts of the world. The share number of these suppliers for informational technology creation gives the company wide variety of choices and the supplier should not increase the prices for services without any reasoning. Furthermore, CubiCasa has established its own in the house development with the team as part of the company, therefore there is no chance of increasing costs for further developments of the application.

Treat of new Entry: The treat of new entry is very high in the industry that is growing at this rate and the basic principle of informational technology is that information is moved fast and obtained quickly, so any company can develop similar application at any time. Quick development of new technologies as AI could improve the processes being carried on by the application with process learning.

Treat of substitution: Substitutions for floor plan can either be the service from other company, providing the same exact service with some different features or a customer who can do it by him/herself with specialized programs, which require prior knowledge of making floor plans, and even more practice when it comes to visual floor plans and 3D plans.

\section{Competitor Analysis}

To better understand the competition of CubiCasa in floor plan makings, let us look at the comparison of the ones the company has compared, table 1.

Table 1: Competitor Analysis

\begin{tabular}{|c|c|c|c|c|}
\cline { 2 - 5 } \multicolumn{1}{c|}{} & Instagram & Facebook & $\begin{array}{c}\text { Google Play } \\
\text { Reviews }\end{array}$ & $\begin{array}{c}\text { App Store } \\
\text { Reviews }\end{array}$ \\
\hline CubiCasa & 613 & 1780 & $3.9(25)$ & $4.7(56)$ \\
\hline MagicPlan & 4693 & 34396 & $4.4(63940)$ & $\begin{array}{c}4.7 \text { Stars } \\
(23800)\end{array}$ \\
\hline RoomSketcher & 2993 & 50768 & $3.2(844)$ & $2.9(26)$ \\
\hline RoomScan pro & $\mathrm{n} / \mathrm{a}$ & 2348 & $\mathrm{n} / \mathrm{a}$ & $4.3(4200)$ \\
\hline By Locometric & $\mathrm{n} / \mathrm{a}$ & 7304 & $\mathrm{n} / \mathrm{a}$ & $\mathrm{n} / \mathrm{a}$ \\
\hline Smartdraw & 3261 & 1757 & $\mathrm{n} / \mathrm{a}$ & $\mathrm{n} / \mathrm{a}$ \\
\hline Roomle & $\mathrm{n} / \mathrm{a}$ & 22665 & $\mathrm{n} / \mathrm{a}$ & $4.1(1023)$ \\
\hline Floorplan pro & 96 & 70 & $\mathrm{n} / \mathrm{a}$ & $4.3(632)$ \\
\hline
\end{tabular}




\section{SWOT Analysis}

To show the strengths, weaknesses, opportunities, and threats the company faces in the floor planning segment, an external analysis with SWOT is performed, table 2.

Table 2: SWOT Analysis

\begin{tabular}{|c|c|c|c|c|}
\hline \multirow{5}{*}{$\begin{array}{l}\text { Overall } \\
\text { Market }\end{array}$} & Strengths & Weaknesses & Opportunities & Threats \\
\hline & $\begin{array}{c}\text { Startup, quick } \\
\text { decision making }\end{array}$ & $\begin{array}{l}\text { Marketing } \\
\text { campaign }\end{array}$ & $\begin{array}{c}\text { Technological } \\
\text { advancement of } \\
\text { the current solution }\end{array}$ & $\begin{array}{l}\text { A high number of } \\
\text { competitors }\end{array}$ \\
\hline & $\begin{array}{l}\text { User-friendly } \\
\text { floor plan maker }\end{array}$ & $\begin{array}{l}\text { Fairly new } \\
\text { application }\end{array}$ & $\begin{array}{l}\text { Acquisition of } \\
\text { company } \\
\text { or technology }\end{array}$ & $\begin{array}{c}\text { Possibility of new } \\
\text { entrants }\end{array}$ \\
\hline & $\begin{array}{l}\text { Being present } \\
\text { in three } \\
\text { continents } \\
\end{array}$ & $\begin{array}{l}\text { Revenue model } \\
\text { and investments. }\end{array}$ & & $\begin{array}{c}\text { New technologies } \\
\text { developed by } \\
\text { competitors } \\
\end{array}$ \\
\hline & & Customer base & & \\
\hline
\end{tabular}

Three main strengths for the overall market are shown in Table 2. Firstly, the company is still in a startup stage and a decision-making can be very due to the fact that the hierarchical structure is not defined and anyone can take the responsibility and introduce new ideas, seen as weekly calls are organized to hear about the new propositions and to try them out. Secondly, the application is very innovative and user friendly. It doesn't take much time and effort to make a floor plan for a reasonable price without any yearly or monthly subscriptions, therefore the customer is not bound to use it until the term ends and pays only for what they use in terms of services. Thirdly, the headquarters are located in three different continents, the main one being in Finland which covers the whole European Union, the second one in Silicon Valley, Unites States of America, covering North America. Third, the Asian market has its subdivision with technical support and technical decision team in Vietnam. These three continents cover the different markets and are positioned around all of the biggest markets. Weaknesses include the fact that the market strategy is not fully defined, which results in marketing decisions that take place on the go and are usually rejected in the end by higher management as unfit for the overall image. This application is still quite young compared to other players in this market and people do not seem to know much about it. Continuing with investment and revenue models, these are not clearly defined and the company is heavily investing its time to search for new investors and participating in pitch competitions. Lastly, the customer base is not yet defined and only a few medium and large companies use the application on a daily basis. Opportunities for the company would be a technologic advancement in simplifying the application even more, or improving the quality of the scans, or bringing the delivery time down than a business day. Furthermore, the acquisition of existing companies with technological superiority could be considered to increase market share and acquire the technology, if the company is in the early stage and could be a potential 
investment. Treats that are apparent are a large number of competitors in all markets, newcomers that appear frequently, and technology created by other companies which might be superior to the existing solutions of CubiCasa and could potentially push the company out.

\section{Conclusion}

This paper has made a deep analysis of the CubiCasa OY. This approach is a contribute for any digital marketing plan that organizations wish to make. Future work is ongoing to define a list of recommendations translated into a full Digital Marketing Plan. Still, from preliminary data, there are several insights that can be presented such as: after assessing the CubiCasa internal and external factors, performing empirical research and analyzing managerial solutions, we concluded that CubiCasa OY is a service provider which has a smartphone application made for floor plan developing with a simple scan via camera. Real estate photographers and agents are the main customers of the company.

CubiCasa generates income by providing a service to its customers via mobile application that creates floor plans. The US is the largest market for CubiCasa OY with 95 per cent of all of the customers based there. PESTEL analysis showed that the technological factors have the most influence on the business, while political, economic, social, ecological, and legal ones come in as secondary influences for the business. Internalization risks that CubiCasa might face are country risk and commercial risk. CubiCasa has many competitors in the same segment and market. SWOT analysis showed that the strength of the company is its position as a startup and weakness stems from possible new competition.

Research findings show that the price of service, the quality of the floor plans, how easy it is to use the application and its accuracy, are the main factors influencing respondents' decision to use an application. Digital media channels used by companies are Facebook, Instagram, Google, and CubiCasa Blog. Keywords, used when searching for an application, identified by respondents, all include floor plan with some variation. Relevant content that respondents would like to see is tutorials and examples.

The market consists of both males and females, representing mostly companies, not individuals. Search engine optimization (SEO) is suggested to passively improve new customers' count and overall standing in the search engine's results page. Search engine marketing (SEM) is suggested in order for the company to appear at the top of the search results when searching for selected keywords. Facebook and Instagram are selected for social media marketing; both content uploading and pay-per-click strategies are considered. Influencer marketing focuses on smaller opinion leaders in real estate market with higher conversation rate. Podcast advertising to advertise on real estate podcast with $30 \mathrm{sec}$. adverts once a month is also suggested. The budget for the period from 2020.01.01 - 2020.12.31 is projected and it is estimated to be around 14,564.00 USD.

\section{References}

- $\quad$ Armstrong, G., Adam, S., Denize, S. and Kotler, P. (2014) Principles of Marketing. Pearson Australia.

- Brown, D., \& Hayes, N. (2008). Influencer Marketing: Who Really Influences Your Customers? (1st ed.). Butterworth-Heinemann.

- Chaffey, D., Chaffey, D., Chaffey, D., \& Chaffey, D. (2020, August 26). RACE marketing model definition - What is? | Digital marketing Glossary. Dr Dave Chaffey : Digital Insights. https://www.davechaffey.com/digitalmarketing-glossary/race-marketingplanningmodel/\#:\%7E:text=RACE\%20is\%20co mmercial\%20based $\% 20$ on,summary\% 20dashboards\%20and\%20continuous $\% 20$ optimization.

- Chaffey, D., \& Ellis-Chadwick, F. (2019). Digital Marketing (7th ed.). Pearson.

- Courtney, H., Kirkland, J. and Viguerie, P. (1997)Strategy under 
uncertainty.Harvard Business Review,75(6), Nov-Dec., 67-79 reprint no. 97603.

- D'amico, H. (2015, April 14). The 6 M's of Mastering Your Integrated Marketing Campaign. Retrieved from https://www.carnegiecomm.com/blog /the-6-ms-of-mastering-yourintegrated-marketing-campaign/

- Dehghani, M. and Tumer, M. (2015) A Research on Effectiveness of Facebook Advertising on Enhancing Purchase Intention of Consumers. Computers in Human Behavior, 49, 597-600.

- Dolan, Robert J. "Note on Marketing Strategy." Harvard Business School Background Note 598-061, October 1997. (Revised November 2000.)

- Gordon, W., Langmaid, R. (1988). Qualitative Market Research: A Practitioner's and Buyer's Guide. Wisconsin University - Madison

- Green, D. C. (2003). Search Engine Marketing: Why it Benefits Us all. Business Information Review, 20(4), 195-202. https://doi.org/10.1177/0266382103 204005

- Hanlon, D., \& Saunders, C. (2007). Marshaling resources to form small new ventures: Toward a more holistic understanding of entrepreneurial support. Entrepreneurship Theory and Practice, 31(4), 619-641.

- Hoffman, D.L., Novak, T.P (2012). Social Media Strategy, in Handbookon
Marketing Strategy, Ed. V. Shankarand G.S. Carpenter.

- Miles, M. B., \& Huberman, M. A. (1994). Qualitative Data Analysis: An Expanded Sourcebook, 2nd Edition (2nd ed.). SAGE Publications, Inc.

- $\quad$ Oliver, R.L. (1999). Whence Consumer Loyalty? Journal of Marketing 6(4), 3334

- Paraskevas, A., Katsogridakis, I., Law, R., \& Buhalis, D. (2011). Search Engine Marketing: Transforming Search Engines into Hotel Distribution Channels. Cornell Hospitality Quarterly, 52(2), 200-208. https://journals.sagepub.com/doi/pdf /10.1177/1938965510395016

- Sirmon, D. G., Hitt, M. A., Ireland, R. D. (2007). Managing Firm Resources in Dynamic Environments to Create Value: Looking Inside the Black Box. Academy of Management ReviewVol. 32, No. 1

- Todor, R. D. (2016). Blending traditional and digital marketing. Bulletin of the Transilvania University of Braşov Series V: Economic Sciences - Vol. 9 (58) No. 1.

- Virtanen, H., Björk, P. and Sjöström, E. (2017), "Follow for follow: marketing of a start-up company on Instagram", Journal of Small Business and Enterprise Development, Vol. 24 No. 3, pp. 468484. https://doi.org/10.1108/JSBED12-2016-0202 